\title{
MINIMALLY INVASIVE ANTEROLATERAL ACCESS ROUTE FOR TOTAL HIP ARTHROPLASTY
}

Rogério Naim Sawaia', Antonio Felipe Martensen Galvão², Fernando Machado Oliveira², Guilherme Rondinelli Secunho², Geraldo Vilela Filho ${ }^{3}$

\section{ABSTRACT}

Objective: The aim of this study was to present a minimally invasive anterolateral access route and to ascertain whether this enables total hip replacement without compromising the quality of the implant positioning, while maintaining the integrity of the gluteus muscles. Method: A retrospective study was conducted on 260 patients (186 females and 74 males) with an average age of 62 years. There were 18 bilateral cases, totaling 278 hips. All the patients had osteoarthritis and had undergone non-cemented total hip arthroplasty (metal-metal or metal-polyethylene) between October 2004 and December 2007. A minimally invasive anterolateral access route was used, measuring 7 to $10 \mathrm{~cm}$ in length, according to body weight and the size of the femoral head. The patients were assessed clinically regarding age, sex and presence of the Trendelenburg sign, and radiologically regarding acetabular and femoral positioning. Results: The acetabular inclination was between $30^{\circ}$ and $40^{\circ}$ in 78 patients, between $41^{\circ}$ and $50^{\circ}$ in 189 patients, and $51^{\circ}$ or over in 11 patients. On anteroposterior radiographs to study femoral positioning, the positioning was central in 209 cases, 41 presented valgus deviation and 28 presented varus deviation. On lateral views, 173 were central, 67 anterior and 38 posterior. The mean duration of the procedure was 63 minutes. Regarding complications, there were five cases of infection, three of deep vein thrombosis, two of hip dislocation, 80 of lengthening of the lower limbs and five of shortening of the operated limb. The Trendelenburg sign was present in four cases, of which one showed superior gluteal nerve injury. Conclusion: The minimally invasive anterolateral access route made it possible to perform total hip arthroplasty without compromising the positioning of the implants, thereby maintaining the integrity of the gluteus muscles.

Keywords - Osteoarthritis/surgery; Arthroplasty, Hip; Surgical Procedures, Minimally Invasive

\section{INTRODUCTION}

Total hip arthroplasty became popular in the 1960s, thanks to Charnley ${ }^{(1)}$. Since then, it has been further perfected through improvements in implants, the development of new materials, and more accurate instruments, as well as improvements in cementing techniques, making arthroplasty one of the most efficient surgeries in orthopedics, with high levels of satisfaction $^{(2)}$. However, the search for better implant materials has not led to a significant decrease of the aggression suffered by patients submitted to this type of procedure.

There is currently a growing concern, among surgeons, to decrease the risks associated with surgery, in the search for a technique that produces less tissue aggression and less bleeding, decreases surgery and hospitalization times, avoids blood transfusion, and enables the patient to be rehabilitated as quickly as

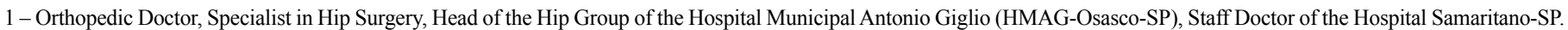

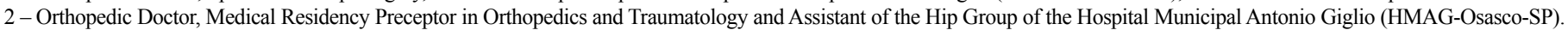

3 - Orthopedic Doctor, Specialist in Hip Surgery at the Hospital Municipal Antonio Giglio (HMAG-Osasco-SP)

Work carried out at the Hospital Municipal Antonio Giglio-Osasco-SP (Head of service: Dr. Marcelo Ubirajara Carneiro) and Hospital Samaritano-SP.

Correspondence: Rua Capote Valente, 154 ap. 61 - Bairro Jardim América - 05409-000 - São Paulo, SP. E-mail: rsawaia@superig.com.br/antoniogalvao@hotmail.com

Work received for publication: August 18, 2010; accepted for publication: November 30/09. 
possible. Analyzing the most commonly used access routes nowadays, like the anterolateral approach of Watson Jones ${ }^{(3)}$, the lateral approach of Hardinge ${ }^{(4)}$ and the posterior approach, it is observed that these incisions are around $20 \mathrm{~cm}$ in length. There is currently a tendency to carry out total hip arthroplasties through minimally invasive incisions of around $8 \mathrm{~cm}$, using a single access route ${ }^{(5)}$.

The objective of this study is to present a minimally invasive anterolateral access route, and to determine whether this route enables total hip arthroplasty to be carried out without compromising the quality of positioning of the implants, maintaining the integrity of the gluteal musculature.

\section{MATERIAL AND METHOD}

A retrospective study was carried out with 288 patients who underwent surgery at Hospital Samaritano (São Paulo) and Hospital Municipal Antonio Giglio (Osasco-SP) during the period of October 2004 to December 2007. Of these, 260 patients were selected, with a total of 278 osteoarthritic hips submitted to total uncemented hip arthroplasty. As criteria for inclusion, records were selected of patients submitted to total uncemented hip arthroplasty for whom there were pre- and post-operative radiographs and full records of outpatient follow-up for at least one year after surgery.

The following were excluded: incomplete records, patients submitted to hybrid and cemented arthroplasties, those who did not maintain adequate follow-up, those with acetabular dysplasias, bone tumors, fractures, positive preoperative Trendelenburg sign, and a body mass index higher than 40, calculated according to the World Health Organization criteria ${ }^{(6,7)}$.

The patients were clinically evaluated in relation to age, sex, presence of Trendelenburg sign, and criteria of ASA, and radiographically, in relation to the position of the acetabular and femoral components.

All the patients were operated on by the same surgical team, using a minimally invasive technique, through an anterolateral incision.

\section{Description of the material}

All the patients were submitted to total hip arthroplasty with uncemented metal-metal or metal-polyethylene prostheses.
The conventional instruments of the basic prosthesis kit were used, together with Hohmann type curved retractors of different widths and angles, hip retractor, reamer and curved acetabular impactor (Figure 1).

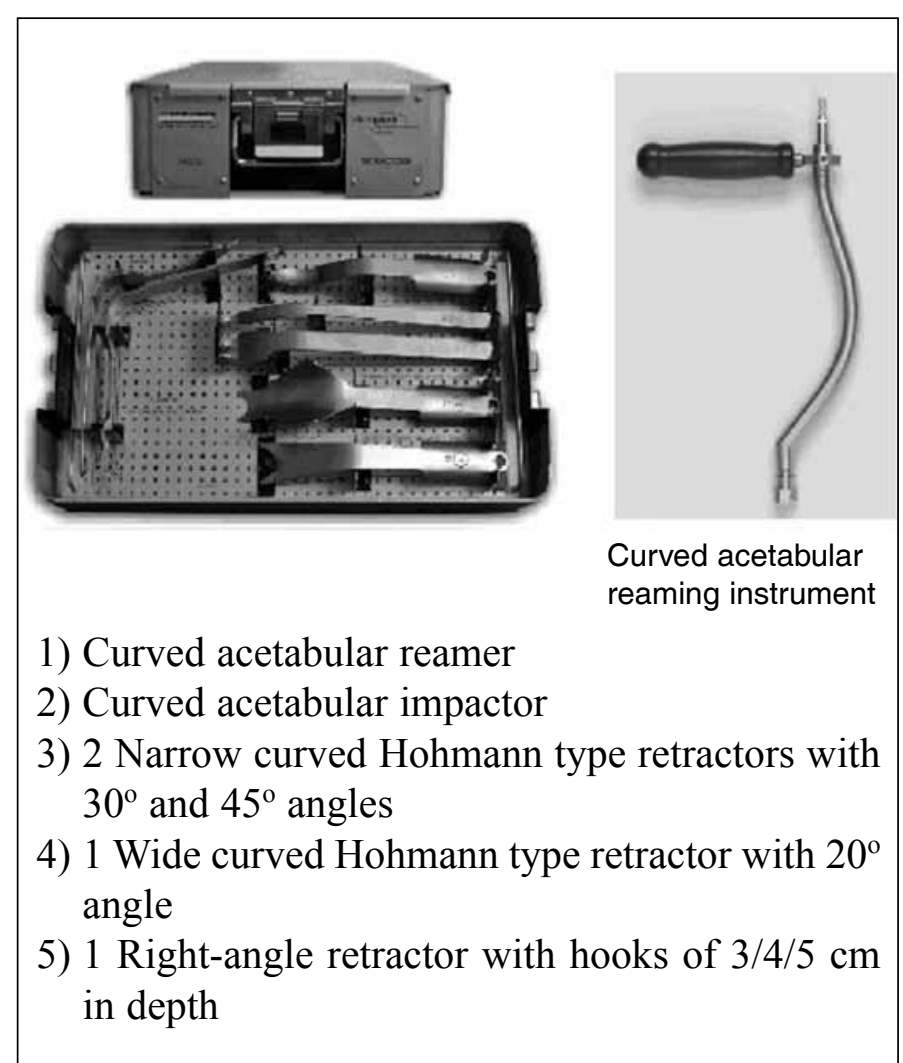

Figure 1 - Curved deep retractors.

\section{SURGICAL TECHNIQUE}

The patient is positioned in lateral decubitus, held in place by two cushions, at $0^{\circ}$ lateral and sagittal inclination (neutral position).

The access route starts at $3 \mathrm{~cm}$ posterior and $1 \mathrm{~cm}$ superior to the prominence of the greater trochanter, moving in an anterior and distal direction at a $45^{\circ}$ angle to the femoral diaphysis, and extending approximately 7 to $10 \mathrm{~cm}$ (Figure 2), the length varying according to body mass and size of the femoral head.

After dissection of the subcutaneous tissue and fascia lata, tenotomy of $4 \mathrm{~cm}$ of the gluteus medius is performed in its myotendinous transition, initiating from medial to lateral. Tenotomy of the gluteus minimus is also performed, and both are retracted upwards, without dissecting the two muscles. The anterior portion of the joint capsule is resected, enabling luxation of the femur head. 


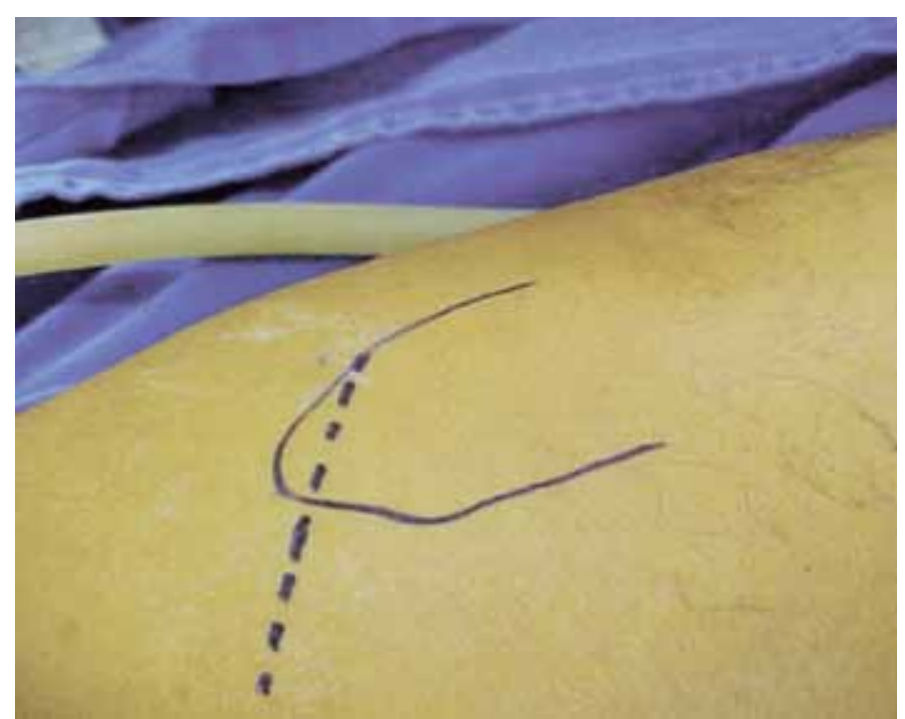

Figure 2 - The access route $3 \mathrm{~cm}$ posterior and $1 \mathrm{~cm}$ superior to the prominence of the greater trochanter, in the anterior direction at a 450 angle to the femoral diaphysis, measuring approximately 7 to $10 \mathrm{~cm}$.

Femoral osteotomy is performed 1 to $2 \mathrm{~cm}$ from the lesser trochanter, according to the preoperative plan.

The modified Hohmann retractors are placed anterior and posterior to the acetabular edge, and the posterior retractor pulls back the greater trochanter to expose the acetabular cavity.

The acetabulum is then reamed using the curved reamer. The acetabular cup is then placed in position (Figure 3).

The preparation of the femur begins by positioning the lower limb at $90^{\circ}$ of hip and knee flexion, with maximum possible external rotation and abduction. The trochanter retractor is positioned on the posterior surface of the trochanteric region, giving a full view

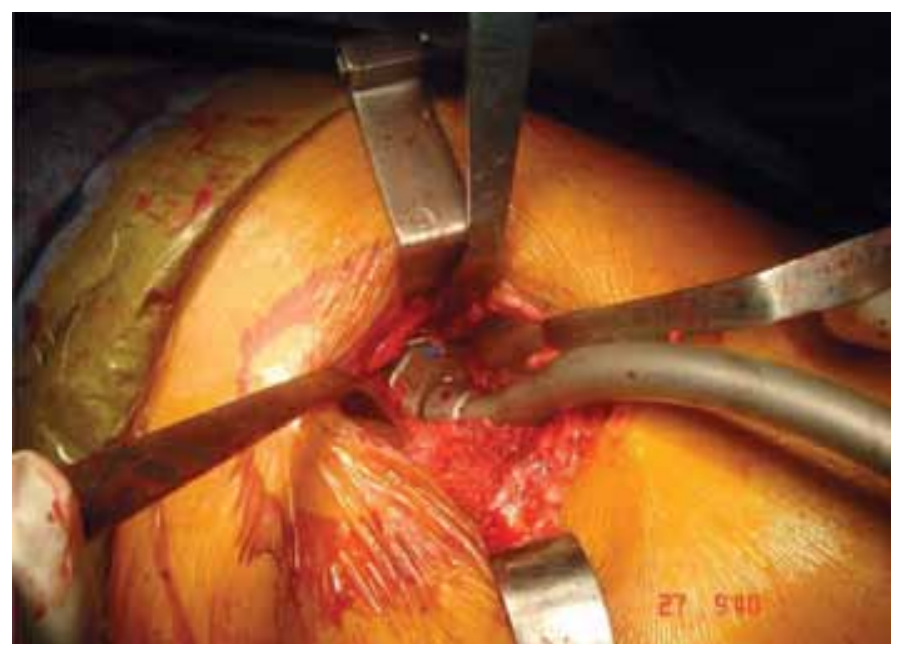

Figure 3 - Positioning of the acetabular cup. of the proximal third of the femur. Femoral reaming is then performed, and the femoral implant is inserted. Next, a stability test is carried out with the provisional head, and only then is the final component inserted. Finally, the wound is closed in layers, and suction drainage inserted. In the postoperative phase, the patient begins motor physiotherapy on the first day and walking training on the second day. The drainage is removed 24 hours after surgery.

\section{EVALUATION OF PATIENTS}

The patients were submitted to pre- and postoperative evaluations. In the pre-operative evaluation, they were evaluated by the $\mathrm{ASA}^{(8)}$ criteria to define the clinical condition. The patients were also evaluated in relation to sex and age, and the Trendelenburg test was performed. For this, the examiner stands behind the patient, asking him or her to flex the knees, keeping the hip extended (to eliminate the action of the psoas muscle). If there is insufficiency of the gluteus medius, a drop in the iliac crest is observed on the same side, due to inability of the contralateral gluteal musculature to contract and lift the pelvis ${ }^{(9)}$.

In the postoperative evaluation, the surgery time was measured from the moment of the initial incision through to complete suture of the skin. The hospitalization period was calculated from admission through to discharge. All the patients were followed-up as outpatients, at 15/30/60/90/180/360 days, in order to evaluate scarring, gait, integration of the implant and Trendelenburg sign. The following postoperative radiograph images were evaluated: anteroposterior pelvis, anteroposterior and profile hip.

The position of the acetabulum was measured on the anteroposterior radiograph of the pelvis based on straight lines drawn from the ischia and acetabular edge. The point where these lines crossed was the angle of positioning of the acetabulum. The femoral positioning was calculated based on a line drawn on the longitudinal axis of the femur, both in the anteroposterior and profile radiographs, and a line in the center of the prosthesis, obtaining an angle between the lines that thus define the position of the implant as central, or with varus or valgus deviation. 


\section{RESULTS}

A total of 260 patients (278 hips) with initial diagnosis of osteoarthritis were submitted to uncemented total hip arthroplasty, 186 female and 74 male, with a minimum age of 52 years, maximum age of 82 years, and a mean age of 62 years (Table 1). A positive Trendelenburg sign was found in four cases, which were submitted to electroneuromyography. Only one patient presented positive electroneuromyography, confirming lesion of the superior gluteal nerve. In this patient, there was lengthening of the lower limb of $3.5 \mathrm{~cm}$. In relation to acetabular inclination, 78 patients had between $30^{\circ}$ and $40^{\circ}, 189$ had between $41^{\circ}$ and $50^{\circ}$ and 11 cases had $51^{\circ}$ or more (Table 2). In relation to femoral positioning in the anteroposterior radiograph, a central positioning was observed in 209 cases, with valgus deviation in 41 and varus deviation in 28 . In the profile radiograph, there were 173 central, 67 anterior and 38 posterior (Figure 4).

Table 1 - Total hips by sex and age.

\begin{tabular}{l|c}
\hline Total patients & 260 \\
\hline Total hips & 278 \\
\hline Male & 74 \\
\hline Female & 186 \\
\hline Mean age & 62 \\
\hline
\end{tabular}

Table 2 - Total patients by acetabular angle.

\begin{tabular}{c|c}
\hline Total patients & Acetabular inclination \\
\hline 78 & $30^{\circ}$ to $40^{\circ}$ \\
\hline 189 & $41^{\circ}$ to $50^{\circ}$ \\
\hline 11 & $>51^{\circ}$ \\
\hline
\end{tabular}

In terms of complications, five cases of infection were observed. Of these, two were submitted to surgical cleaning resulting in total improvement, and three had to be submitted to surgical cleaning with insertion of the retractor and performing the total hip prosthesis in a second surgery. There were three cases of deep vein thrombosis, confirmed by vein contrast echo Doppler, and two cases of hip luxation. 80 cases were found with lengthening of the lower limbs, with values less than $0.5 \mathrm{~cm}$, and only seven had lengthening greater than $2 \mathrm{~cm}$ Five cases were Rev Bras Ortop. 2011;46(2):183-8 also observed with shortening of the operated limb, but all with less than $1 \mathrm{~cm}$, which corroborates the results found in the literature ${ }^{(10-12)}$.

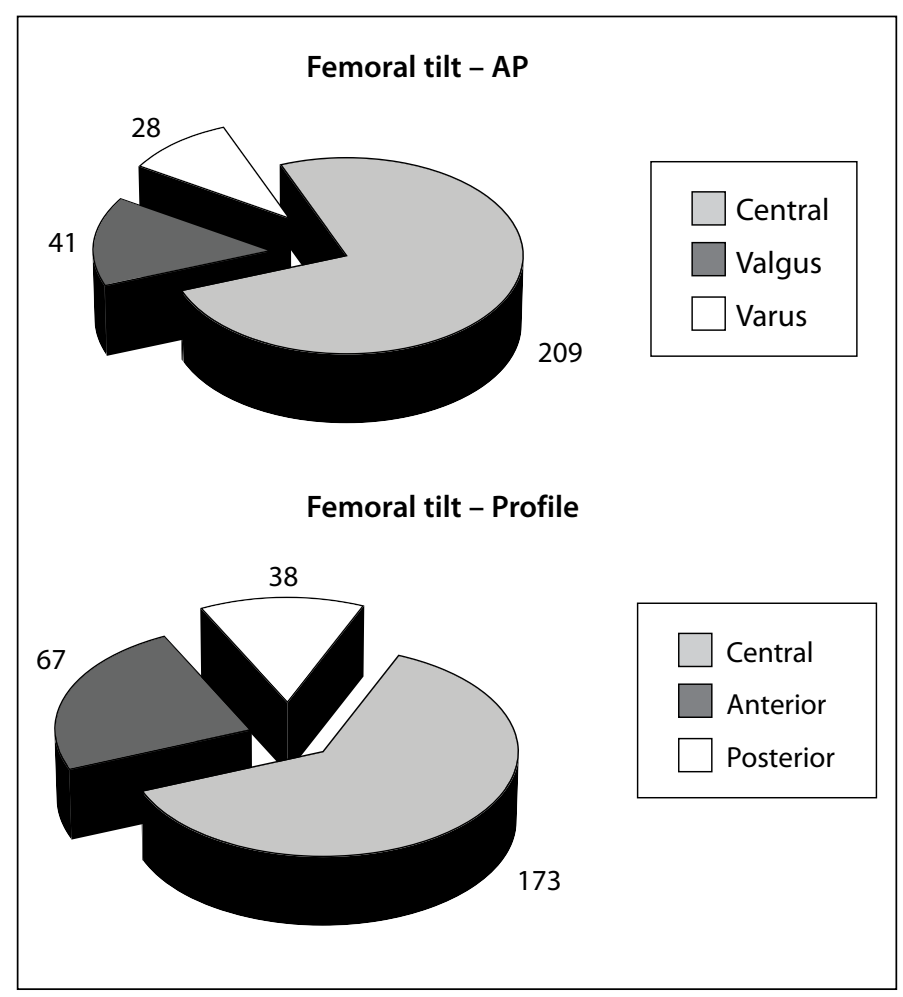

Figure $4-$ Femoral positioning in the anteroposterior and profile radiographs.

\section{DISCUSSION}

From 2002(13), minimally invasive techniques for total hip arthroplasty began to increase in popularity, publicized by the non-medical media in articles on the Internet and newspapers, as well as in specialist magazines, which saw a huge increase of articles on these new techniques. This led to a demand, by both surgeons and patients, for mini-incision, which promised a less aggressive surgery, with little pain and faster recovery time. With information gathered from the internet, candidate patients for hip arthroplasty practically forced surgeons to make smaller incisions, and the competition between surgeons for the smallest incision became common ${ }^{(14)}$.

Obviously, like all new techniques, complications arose during the learning curve, such as failures in the positioning of the implants, necrosis of the surgical border with an increase in levels of infection, luxations, occult bleeding, and a dis- 
parity between the limbs ${ }^{(15,16)}$ and at the start of the learning curve, it was common for surgeons to start with a small skin incision and end with a bigger one, leading to greater tissue lesion due to the difficulties associated with the smaller access route. The literature corroborates these facts, ending the euphoria, leading surgeons to rethink this technique which brought out complications that had already been overcome by the conventional techniques. Analyzing these facts in detail, the learning curve was the first main hurdle. Naturally, any new technique requires a phase of initial training, when the level of errors is higher, due to the difficulty in visualizing the points of reference, which were previously easy to find using the traditional methods, but which were now obscured with the minimally invasive routes, even in the hands of surgeons who were highly skilled, but who were still accustomed to the $20 \mathrm{~cm}$ access route.

Another important point is to the instruments used to perform the prosthesis, not specifically the implants, but the actual instruments used. Due to the small incision size, the instruments also had to be adjusted to facilitate the minimally invasive technique for the surgeon. In this series, retractors with curvature and various angles were used to facilitate the surgical approach, as well as acetabular reamers and impactors to assist in the preparation of the bone and positioning of the implant. Without these instruments, the acetabulum would frequently be positioned with a vertical inclination.

The use of this anterolateral route together with the specialized material enabled the incision to be taken full advantage of, both in the acetabular and femoral preparations, as the latter is at a $45^{\circ}$ angle to the femoral diaphysis, making the entire length of the route available and enabling the adequate preparation of bone adequately for the implants.

A constant criticism in relation to the anterior and lateral access is the need to deinsert the abductor musculature, particularly the gluteus medius muscle, and the probability of lesion of the superior gluteal nerve, which can lead to gluteal insufficiency, which is clinically evidenced by claudication on walking and Trendelenburg sign. Analyzing the results in this series, the Trendelenburg sign was present in four cases (2\%). All these cases were submitted to electroneuromyography, and lesion of the superior gluteal nerve was observed in only one. There are works that cite a positive Trendelenburg percentage of up to $20 \%$ after two years of follow-up ${ }^{(17)}$.

In relation to the positioning of the implants, an average acetabular angle of $41^{\circ}-50^{\circ}$ was observed, which shows a level that is within the ideal mean value cited in the literature ${ }^{(18)}$, both for traditional direct lateral access, and for anterior access ${ }^{(19)}$ and this value is also similar to the results obtained using the navigation system ${ }^{(20)}$. With regard to the femoral positioning, it was observed that $75 \%$ of the shafts were positioned in the ideal manner. In other minimally invasive accesses, a varus positioning was found in up to $12 \%^{(21,22)}$.

For surgery time, a maximum time of 90 minutes was observed, and a minimum of 35 minutes, with a mean time of 63 minutes. The literature cites an increase in surgical time using traditional access in relation to the minimally invasive posterior route, which would be due to the time spending opening and closing the surgical layers ${ }^{(23-26)}$. Anterior accesses with mean times of 60.4 minutes $60,4^{(27)}$ and 75 minutes $^{(18)}$ are also cited. Extremely low means were also found, such as 37.5 minutes $^{(24)}$ and 57 minutes $^{(28)}$, in which the author benefited from preoperative planning to define the osteotomy of the femoral neck. With practice, the mini-incision inevitably minimizes the surgery time, since its smaller size reduces the time it takes to open and close the soft tissues ${ }^{(26)}$. The reduced surgery time clearly brings advantages, reducing the anesthesia time and the amount of drugs administered to the patient, decreasing the exposure time, and consequently, lowering the risk of infection. The surgery time should not be prolonged, but it should not be the main focus in surgery of total hip arthroplasty. It is understood that the procedure time decreases with the improvement and practice of the surgeon and the team, over the learning curve. The main objective of arthroplasty is to perform surgery to re-establish the center of rotation and good positioning of the implants. The choice of a minimally invasive access route should not compromise the success of the procedure. 
Some factors of great importance that were not studied here should also be taken into consideration when discussing mini-incision in total hip arthroplasty. The decrease in bleeding, pain and rehabilitation time are great advantages of this surgical approach over other traditional approaches. The importance of protocols is emphasized in the preparation of the patient, both prior to surgery and in the rehabilitation and control of pain, which has brought proven benefits for patients submitted to this type of surgery.

\section{CONCLUSIONS}

1. The minimally invasive anterolateral access route enables consecrated hip joint replacement surgery to be carried out safely.

2. It does not affect the quality of the positioning of the implants, and it preserves the gluteal musculature intact.

3. It is extremely important to have appropriate instruments and a surgical team that is trained to carry out the minimally invasive technique.

\section{REFERENCES}

1. Charnley J. Arthroplasty of the hip: a new operation. Lancet. 1961;1:1129-32.

2. Queiroz D. Mini incisão lateral para artloplastia total do quadril. Técnicas em Ortopedia HSPE. 2003;3(1):13-20.

3. Watson-Jones R. Fractures of the neck of the femur. $\mathrm{Br} J$ Surg 1935/1936;23:787-808.

4. Hardinge K. The posterolateral approach to the hip joint. AAOS Instr Course Lect. 1953;10:175.

5. Lester K, Helm M. Mini-incision posterior approach for hip arthroplasty. Orthop Traumatol. 2001;9:245-53.

6. Black D, James WP, Besser GM. Obesity. J Roy Coll Phys London. 1983;17(1):5-65.

7. World Health Organization regional office for Europa. Nutrition Body mass index-BMI. Available at: http://www.euro.who

8. American Society of Anesthesiologists. New classification of physical status. Anesthesiology. 1963;24:111.

9. Trendelenburg F. Ueber den Gang bei angeborener Hüftgelenksluxation. Dtsch Med Wochenschr. 1895;21:21-4

10. Glassman $\mathrm{AH}$. Engh CA. The removal of porous-coated femoral hip stems. In: Callaghan JJ, Rosenberg AG, Rubash HE, editors. The adult hip. 2nd. Philadelphia: Lippincott Williams \& Wilkins; 2007. p.1159.

11. Turula KB, Friberg O, Lindholm TS, Tallroth K, Vankka E. Leg length inequality after total hip arthroplasty. Clin Orthop Relat Res. 1986;(202):163-8.

12. Woolson ST. Leg lengh equalization during total hip replacement. Orthopedics. 1990;13(1):17-21.

13. Wenz JF, Gurkan I, Jibodh SR. Mini-incision total hip arthroplasty: a comparative assessment of perioperative outcomes. Orthopedics. 2002;25(10):1031-43.

14. Klein GR, Parvisi J, Sharkey PF, Rothman RH, Hozack WJ. Minimally invasive total hip arthroplasty: internet claims made by members of the Hip Society. Clin Orthop Relat Res. 2005;441:68-70.

15. Rosencher N, Kerkkamp HEM, Macheras G, Munuera LM, Menichella G, Barton DM et al. Orthopedic Surgery Transfusion Hemoglobin European Overview (OSTHEO) study: blood management in elective knee and hip arthroplasty in Europe. Transfusion. 2003;43(4):459-69.

16. Bal BS, Haltom D, Aleto T, Barrett M. Early complications of primary total hip replacement performed with a two-incision minimally invasive technique. J Bone Joint Surg Am. 2005;87(11):2432-38.

17. Picado $\mathrm{CH}$, Garcia FL, Marques W Jr. Damage to the superior gluteal nerve after direct lateral approach to the hip. Clin Orthop Relat Res. 2007;455:209-11.

18. Matta JM, Shahrdar C, Ferguson T. Single-incision anterior approach for total hip arthroplasty on an orthopaedic table. Clin Orthop Relat Res. 2005;441:115-24.

19. de Beer J, Petruccelli D, Zalzal P, Winemaker MJ. Single-incision, minimally invasive total hip arthroplasty: length doesn't matter. J Arthroplasty. 2004;19(8):945-50.

20. DiGioia AM 3rd, Plakseychuk AY, Levison TJ, Jaramaz B. Mini-incision technique for total hip arthroplasty with navigation. J Arthroplasty. 2003;18(2):123-8.

21. Woolson ST, Mow CS, Syquia JF, Lannin JV, Schurman DJ. Comparison of primary total hip replacements performed with a standard incision or a miniincision. J Bone Joint Surg Am. 2004;86(7):1353-8.

22. McLaughlin JR, Lee KR. Total hip arthroplasty with an uncemented femoral component. Excellent results at ten-year follow-up. J Bone Joint Surg Br. 1997;79(6):900-7.

23. Ogonda L, Wilson R, Archbold P, Lawlor M, Humphreys $\mathrm{P}, \mathrm{O}$ 'Brien $\mathrm{S}$ et al. A minimal-incision technique in total hip arthroplasty does not improve early postoperative outcomes. A prospective, randomized, controlled trial. J Bone Joint Surg Am. 2005;87(4):701-10.

24. Hartzband MA. Posterolateral minimal incision for total hip replacement: technique and early results. Orthop Clin North Am. 2004;35(2):119-29.

25. Inaba Y, Dorr L, Wan Z, Sirianni L, Boutary M. Operative and patient care techniques for posterior mini-incision total hip arthroplasty. Clin Orthop Relat Res. 2005;441:104-14.

26. Vicente JRN. Estudo comparativo entre a técnica minimamente invasiva posterior e a via de acesso lateral direta nas artroplastias totais do quadril não cimentada [tese]. São Paulo: Faculdade de Medicina, Universidade de São Paulo; 2007.

27. Kennon RE, Keggi JM, Wetmore RS, Zatorski LE, Huo MH, Keggi KJ. Total hip arthroplasty through a minimally invasive anterior surgical approach. J Bone Joint Surg Am. 2003;85(Suppl 4):39-48.

28. Goldstein WM, Branson JJ, Berland KA, Gordon AC. Minimal-incision total hip arthroplasty. J Bone Joint Surg Am. 2003;85(Suppl 4):33-8. 